Illinois State University

ISU ReD: Research and eData

Theses and Dissertations

$2-27-2017$

\title{
Examining Fifth-Grade In-School Physical Activity Patterns and How Many Days of Monitoring are Needed
}

Tyler R. Langosch

Illinois State University, tlangosch@gmail.com

Follow this and additional works at: https://ir.library.illinoisstate.edu/etd

Part of the Elementary and Middle and Secondary Education Administration Commons, Elementary Education and Teaching Commons, and the Other Education Commons

\section{Recommended Citation}

Langosch, Tyler R., "Examining Fifth-Grade In-School Physical Activity Patterns and How Many Days of Monitoring are Needed" (2017). Theses and Dissertations. 691.

https://ir.library.illinoisstate.edu/etd/691

This Thesis is brought to you for free and open access by ISU ReD: Research and eData. It has been accepted for inclusion in Theses and Dissertations by an authorized administrator of ISU ReD: Research and eData. For more information, please contact ISUReD@ilstu.edu. 


\title{
EXAMINING FIFTH-GRADE IN-SCHOOL PHYSICAL ACTIVITY PATTERNS \\ AND HOW MANY DAYS OF MONITORING ARE NEEDED
}

\author{
Tyler R. Langosch
}

46 Pages

PURPOSE: The purpose of the study was to examine in-school physical activity patterns among fifth-grade students residing in a Midwestern community. A secondary purpose of this study was to determine the minimum number of days necessary to estimate mean physical activity levels, as both moderate-to-vigorous physical activity (MVPA) and steps per day, in fifth-grade students using objective physical activity monitors across two semesters. METHODS: Activity patterns were assessed during two school semesters, spring $(\mathrm{N}=88$ boys \& 91 girls) and fall ( $\mathrm{N}=92$ boys \& 94 girls), from 10-12 year old fifth-grade students in four Midwestern elementary schools. Data was collected using wrist worn activity trackers. The devices were administered by teachers at the start of each school day and collected at the end of each school day for two consecutive weeks. Variables observed were minutes of vigorous + activity, vigorous activity, moderate activity, easy activity and very easy activity along with steps and calories expended. Demographic and anthropometric data were also recorded (age, height, weight). All data was uploaded to the device website database and then collected by the primary researcher. Physical activity measures were surveyed and compared across the four different schools, semesters and genders. In the secondary analysis, steps and MVPA were examined, individually, with Cronbach's alpha to determine how many days of measurement were needed to assess mean activity patterns. RESULTS: Average in-school MVPA for boys in the fall 
semester accounted for $79.2 \%$ of the daily recommendation ( 47.5 of the 60 minutes), for girls, in-school MVPA accounted for $69.1 \%$ of the daily recommendation (41.49 of the 60 minutes). During the spring semester, boys attained $74.4 \%$ or 44.64 minutes of their MVPA in-school, while girls attained $60.5 \%$ or 36.27 minutes of their MVPA in-school. Average steps measured in-school during the fall semester was 7,491 or $57 \%$ of total daily recommendation, average steps measured during the spring semester was 7,006 or $54 \%$ of the daily recommendation. The reliability analysis suggested that at least four days of measurement were needed to achieve an alpha of 0.80 for both steps $(\alpha=0.825,95 \%$ CI [0.777-0.865]) and MVPA $(\alpha=0.839,95 \%$ CI [0.795-0.87]) during spring collection. During the fall semester, at least four days were also necessary to achieve a reliability of 0.80 in steps ( $\alpha=0.803,95 \%$ CI [0.751-0.846]) and MVPA $(\alpha=0.811,95 \%$ CI $[0.761-0.852])$. However, fall five-day activity patterns did exhibit greater variability than four-day activity patterns in both steps $(\alpha=0.784,95 \%$ CI $[0.730-0.830])$ and MVPA $(\alpha=0.794,95 \%$ CI $[0.742-0.838])$. CONCLUSIONS: Our results show that boys attained more steps and minutes of MVPA during both semesters of collection than girls. Both reached appropriate levels of activity in-school, allowing them optimal opportunity out of school to reach daily activity goals. These results also indicate that four-day activity monitoring protocols reliably estimate the mean in-school physical activity patterns, steps and MVPA, in fifth grades students. It should be noted that the results indicate consistency was not improved by a fifth day of measurement in steps and MVPA during a five-day collection period.

KEYWORDS: Physical Activity, In-School, Elementary 
EXAMINING FIFTH-GRADE IN-SCHOOL PHYSICAL ACTIVITY PATTERNS

AND HOW MANY DAYS OF MONITORING ARE NEEDED

TYLER R. LANGOSCH

A Thesis Submitted in Partial

Fulfillment of the Requirements

for the Degree of

MASTER OF SCIENCE

School of Kinesiology and Recreation

ILLINOIS STATE UNIVERSITY

2017 
Copyright 2017 Tyler R. Langosch 
EXAMINING FIFTH-GRADE IN-SCHOOL PHYSICAL ACTIVITY PATTERNS AND HOW MANY DAYS OF MONITORING ARE NEEDED

TYLER R. LANGOSCH

COMMITTEE MEMBERS:

Dale D. Brown, Co-Chair

Kelly R. Laurson, Co-Chair

Skip M. Williams 


\section{ACKNOWLEDGMENTS}

I would like to thank the members of my committee, Dr. Dale D. Brown, Dr. Kelly R. Laurson and Dr. Skip M. Williams for their guidance and support on this project. Also, thank you to Susann Marcum and the $5^{\text {th }}$ grade classroom teachers in charge of administration and collection of the activity monitors.

T. R. L. 


\section{CONTENTS}

Page

ACKNOWLEDGMENTS

$\begin{array}{ll}\text { CONTENTS } & \text { ii }\end{array}$

$\begin{array}{lll}\text { TABLES } & \text { iii }\end{array}$

CHAPTER I: EXAMINING FIFTH-GRADE IN-SCHOOL PHYSICAL ACTIVITY

PATTERNS AND HOW MANY DAYS OF MONITORING ARE NEEDED 1

$\begin{array}{ll}\text { Introduction } & 1\end{array}$

$\begin{array}{ll}\text { Methods } & 6\end{array}$

$\begin{array}{ll}\text { Subjects and Procedures } & 6\end{array}$

$\begin{array}{ll}\text { Data/Statistical Analysis } & 7\end{array}$

$\begin{array}{ll}\text { Results } & 8\end{array}$

$\begin{array}{ll}\text { Discussion } & 10\end{array}$

$\begin{array}{ll}\text { Conclusions } & 15\end{array}$

$\begin{array}{ll}\text { References } & 20\end{array}$

CHAPTER II: EXTENDED REVIEW OF THE LITERATURE 22

$\begin{array}{ll}\text { Specific Research } & 22\end{array}$

$\begin{array}{ll}\text { Summary } & 41\end{array}$

$\begin{array}{ll}\text { References } & 43\end{array}$ 


\section{TABLES}

Table Page

1. Characteristics of Subjects (Means \pm S.D.) 17

2. Averages for In-School Physical Activity Measures: Semesters and Genders 18

3. Intraclass Correlation Coefficient Tables for MVPA and Steps 19

4. Differences Between Semesters: MVPA and Steps (Genders Combined) 19 


\section{CHAPTER I: EXAMINING FIFTH-GRADE IN-SCHOOL PHYSICAL ACTIVITY PATTERNS AND HOW MANY DAYS OF MONITORING ARE NEEDED}

\section{Introduction}

Obesity is now recognized as a disease and it is becoming more prevalent early on in life. From 2011-2014, the prevalence of obesity was just over 36\% in adults and 17\% in youth (Ogden et al., 2015). Currently, 12.7 million children and adolescents are affected by obesity. As boys and girls transition from elementary to middle school, those who participate in higher levels of moderate to vigorous physical activity (MVPA) maintain more favorable levels of adiposity and weight status (Dowda et al., 2017). Previous research shows that MVPA is significantly and negatively associated with fat mass index, percent body fat and body mass index (Dowda et al., 2017). Monitoring and analyzing physical activity levels in children can truly show how much activity they are getting each day and how much they need to improve on in order to meet their requirement of 60 minutes/day. Doing so can help reduce obesity risk. Knowing the consequences of obesity such as: increased blood pressure, high cholesterol, impaired glucose intolerance, insulin resistance, breathing problems, sleep apnea, joint problems, low self-esteem and social problem, it is important for schools to promote physical activity daily. Outside of the schools encouragement to participate in physical activity is also very important. Research shows that the parent child relationship of inactivity is highly correlated, more so than the relationship between that of vigorous activity (Bohr et al., 2012). Therefore parents who want to reduce their children's inactivity should be paying more attention to their own habits and lifestyle as well.

Exercise and increased activity has numerous physical benefits, it also produces many psychological benefits as well, including classroom performance improvement. Physical activity 
levels are significantly related to self-esteem, an increase in vigorous physical activity levels is associated with progressive improvements in self-esteem for both males and females (Tremblay et al., 2000). Classroom physical activity appears to be a promising strategy for improving attention in the classroom as well. Teachers who implement classroom physical activity breaks have higher levels of student agreement and increased behavior benefits from physical activity than teachers who do not use any physical activity implementations (Carlson et al., 2013). Curriculum-based physical activity in-school may improve the academic achievement and psychological health of children. Lastly, Considerable evidence indicates that children's engagement in physical activity during adolescence is an important determinant of cognitive function and structural development of the brain (Carlson et al., 2015).

Understanding that boys and girls are different and they each have different understandings and interests when it comes to physical activity it is imperative to observe the variance in activity patterns between the genders. Using the information, interventions can be used for different genders to ensure that each student is getting the most physical activity possible throughout the day. Recent data from suburban Cook County, IL schools shows that on average, boys receive approximately 20 minutes of MVPA/day while girls only received approximately 11 minutes of MVPA/day (Kwon et al., 2014). Other research has produced findings that go along with the fact that across grades, boys are consistently more active than girls when it comes to overall active time. However, when intensity of activity is taken into consideration boys and girls do not differ substantially. Girls tend to participate in higher amounts of moderate activity while boys tend to spend more time in the vigorous category. The daily gender gap between boys and girls for vigorous physical activity was found to be $45 \%$ 
while the gap between genders for moderate to vigorous activity was only $11 \%$ (Trost et al., 2000).

Physical activity is a key factor of health and wellness for people of all ages in the United States. Regular, habitual physical activity is one of the most important things an individual can do for their health. According to the CDC it can control weight, reduce cardiovascular disease risk, reduce risk of type 2 diabetes, reduce risk of some cancers, improve mental health and mood, improves the ability to perform daily activities and increases the chances of living longer. Data very strongly supports an inverse association between physical activity and all-cause mortality. Active individuals, both men and women, have approximately a 30\% lower risk of dying during follow-up, compared with inactive individuals (Haskell, et al., 2008). Continuing evidence indicates that it may be the overall volume of energy expended, regardless of which activities produce this energy expenditure that is important to lower the risk of mortality. With extensive evidence indicating that increased physical activity patterns can lead to overall health benefits as well as the decrease in all-cause mortality, it is essential to incorporate exercise and movement into daily routines. As individuals age, priorities shift, and less time is spent being physically active. Among adolescents, physical activity patterns generally decrease most from ages 15 through 18. Also, the "regular, vigorous activity" and strength building patterns decline consistently from ages 12 through 21 (Caspersen et al., 2000). To build habits of physical activity, it is important to expose children to high volumes of movement early and often in their lives. Allowing children to feel comfortable and have fun being physically active is an easy way to promote increased activity patterns into early adolescence all the way through adulthood.

Increased movement and exercise has been proven to decrease numerous health risks. Many schools throughout the U.S. are beginning promotional programs that incorporate 
increased physical activity throughout the day, aside from physical education and recess classes. Exercise aids in decreasing obesity rates in children and adults, obesity is now recognized as a disease, in itself, by the American Medical Association. A high prevalence of obesity in children leads to a high prevalence of obesity in adolescents and adulthood. Incorporating regular, habitual physical activity not only promotes many health benefits, it also provides many psychological rewards as well.

A report done by the Centers for Disease Control and Prevention shows alarming results for physical activity patterns in youth. Only $27 \%$ of students accumulate 60 minutes of physical activity daily and only $52 \%$ of students participate in muscle strengthening activities. While $41 \%$ of students play video or computer games for 3 or more hours per day and $32 \%$ of students watch television 3 or more hours per day. Physical activity is a learned behavior and is best promoted by family, teachers and students' environment. When children are exposed to activity at a young age they are prone to remain active throughout their life. Evidence shows that physical activity can have a beneficial effect on body composition, cholesterol, blood pressure, blood sugar, aerobic fitness, muscular strength, movement skills, and bone health (Haskell et al., 2008). According to the American College of Sports Medicine, children and adolescents should accumulate a minimum of 60 minutes of physical activity (MVPA) daily as part of transportation, physical education, sport, free play and planned exercise. The activities should be a combination of moderate and vigorous intensity. To promote and maintain health, all healthy adults aged 18 to 65 years old need moderate-intensity aerobic physical activity for a minimum of 30 min on five days each week or vigorous-intensity aerobic physical activity for a minimum of $20 \mathrm{~min}$ on three days each week. In addition, every adult should perform activities that maintain or increase muscular strength and endurance a minimum of two days each week 
(Haskell et al., 2007). Because of the dose-response relationship between physical activity and health, the CDC reports that individuals who wish to further improve their personal fitness, reduce their risk for chronic diseases and disabilities or prevent unhealthy weight gain may benefit by exceeding the minimum recommended amounts of physical activity furthering the importance of physical activity promotion and monitoring at a young age.

Nationwide, schools are focusing on implementing physical activity into their scheduled coursework. Teachers and administrators are turning more attention to getting the students more active in their everyday classes, along with P.E. and recess, which are predominantly active classes. Research shows that the more methods used to promote physical activity a school uses, the more MVPA is achieved on average by its students. Schools use methods such as promotion of classroom MVPA, structured activities are given during recess, less than 30 children in a P.E. class and students attend more than 100 minutes of MVPA per week (Fu et al., 2016). Students in classrooms with activity breaks are more likely to obtain 30 minutes per day of MVPA during school. Also, students provided with 3-4 physical activity opportunities (classroom breaks, recess, physical education, and a specific physical education teacher) had on average 5 more minutes of in-school MVPA than student without those opportunities (Adkins et al., 2015). Implementing classroom in-school physical activity breaks can improve student physical activity during school as well as behavior in the classroom. The more active children can be in-school, the less reliant they are on out of school physical activities to achieve their daily goal of 60 minutes of MVPA. If children can reach more than half of their daily MVPA during school hours it is more feasible for them to accomplish the remaining 30 minutes outside of school.

Further research is necessary to continue to understand elementary grade level in-school physical activity patterns in order to provide adjustments and make improvements where needed. 
Determining the appropriate amount of days of activity monitoring is essential in order to complete a valid and reliable study. Children in grades 1-6 exhibit less day to day variability in MVPA behavior, analyses indicate that 4-5 days of monitoring for these students would represent a valid interpretation of their daily average. Older children tend to have higher variability in day to day activities and require a recommended 8-9 days of monitoring to produce acceptable estimates of daily activity participation (Trost et al., 2000).

Therefore, the primary purpose of this study is to examine and compare fifth grade, inschool physical activity between genders and semesters of collection (time of year) to determine significant patterns in their activity. A secondary goal of this project is to determine how many days of in-school physical activity monitoring are needed to account for an accurate mean measurement.

\section{Methods}

\section{Subjects and Procedures}

Physical activity data was collected during the two semesters of the school year, fall and spring. Most of the subjects participated in both semesters, some did not due to various reasons: school changes, absences, etc. The subjects in this study included 186 fifth grade students in the fall semester and 179 fifth grade students in the spring semester from 4 different elementary schools in a Midwest U.S. school district. The four schools used were similar demographically. Of the 186 students that participated in the fall, 92 were males and 94 were females with ages ranging from 10-12 years old. Of the 179 students that participated in the spring semester 88 were male and 91 were female, again with ages ranging from 10-12 years old. Activity monitors (Polar Active, Polar Electro Inc. Kempele, Finland) were assigned to each student and each received a de-identified code to ensure confidentiality. Each school received the monitors one at 
a time, therefore the weeks of collection were not uniform across all schools. The monitors were distributed to the students at the beginning of each school day and collected at the end of each school day by their individual classroom teachers. This process was repeated for two weeks to achieve a total of 10 days of monitoring (excluding weekend days). At the end of the monitoring period, each teacher uploaded their class data to the monitor's website (PolarGoFit.com) which could then be accessed by the primary researchers. Once all data collection was completed, the data for each class was compiled into one master document. This original document contained data for each student for each day of monitoring. The document contained each student's data for the following variables: steps, calories, total wear time, MVPA minutes, vigorous + minutes, vigorous minutes, moderate minutes, easy minutes and very easy minutes. Also recorded were the students' school, gender, age, height, weight, and calculated BMI. The researchers compiled each class into one master document containing all days of data for each individual student.

\section{Data/Statistical Analysis}

Descriptive statistics were used to describe the subject demographics. The data was examined and any days in which a student obtained less than 500 steps, less than 300 minutes of wear time or greater than 460 minutes of wear time were excluded from the file. Remaining were what the researchers classified as "quality days" of data. Physical activity averages were calculated for each student based on their quality days of collection. The data was then separated by semester, fall and spring, and then organized by gender.

To assess the mean differences for all variables of physical activity (MVPA, steps, calories, vigorous + minutes, vigorous minutes, moderate minutes, easy minutes and very easy minutes) between genders during each semester, t-tests were performed. The data was analyzed to see how in-school student physical activity contributed to the goal of at least 60 minutes of 
MVPA/day. Also, observations were made regarding the patterns of physical activity between genders as well as how in-school physical activity changed between the fall and the spring semesters of measurement.

The amount of days needed to obtain a quality in-school physical activity measurement was also assessed. Reliability analysis using Cronbach's alpha was used to determine the amount of days that most accurately depicted a student's average physical activity. The two measures of physical activity assessed in this analysis were MVPA minutes and steps/day. An intraclass correlation coefficient $>0.800$ was used to depict a reliable measurement of average physical activity. Data was analyzed from two, three, four, and five days of collection. Data from this study was analyzed using IBM SPSS Statistics Version 20 (Armonk, New York) as well as Microsoft Excel.

\section{Results}

The sample in this study consisted of 186 fifth grade students during the fall collection ( 92 boys, 94 girls) and 179 fifth grade students during spring collection ( 88 boys, 91 girls). The subjects in the fall had a mean age of $10.6 \pm 0.5$ years and a body mass index (BMI) of $19.2 \pm$ $4.3 \mathrm{~kg} / \mathrm{m}^{2}$ (boys: $10.7 \pm 0.5$ years of age, BMI $19.3 \pm 4.3 \mathrm{~kg} / \mathrm{m}^{2}$, girls: $10.6 \pm 0.5$ years of age, BMI $\left.19.1 \pm 4.3 \mathrm{~kg} / \mathrm{m}^{2}\right)$. The subjects in the spring had a mean age of $10.9 \pm 0.4$ years and a BMI of $19.1 \pm 4.1 \mathrm{~kg} / \mathrm{m}^{2}$ (boys: $11.1 \pm 0.4$ years of age, BMI $19.3 \pm 4.2 \mathrm{~kg} / \mathrm{m}^{2}$, girls: $10.9 \pm 0.3$ years of age, BMI $18.9 \pm 4.1 \mathrm{~kg} / \mathrm{m}^{2}$ ). Descriptive statistics for the subjects are reported in Table 1 .

During the fall measurement, it was found that students of both genders achieved on average 44.4 minutes of MVPA during the school day which accounted for $74 \%$ of their daily recommendation of 60 minutes. The students also averaged 7,491 steps/school day as well as 1,649 calories expended. When comparing gender differences, t-test results show significant 
differences in MVPA at the 0.01 alpha level with boys averaging 47.5 minutes of MVPA (79\% of daily requirement) and girls averaging 41.5 minutes (69\% of daily requirement). Results also showed significant differences between genders for steps taken during the school day at the 0.01 alpha level with boys averaging 7,800 steps and girls averaging 7,188 steps. There was no significant difference found between calories expended, with boys averaging 1,775 calories and girls averaging 1,526 calories. Results for all categories of physical activity (MVPA, steps, calories, vigorous + minutes, vigorous minutes, moderate minutes, easy minutes and very easy minutes) can be seen in Table 2 .

During the spring measurement, students of both genders achieved an average of 40.38 minutes of MVPA during the school day which accounted for $67 \%$ of their daily recommendation of 60 minutes. The students also averaged 7,006 steps/school day as well as 1,622 calories expended. When comparing gender differences, t-test results show significant differences in MVPA at the 0.01 alpha level with boys averaging 44.6 minutes of MVPA (74\%) and girls averaging 36.3 minutes (60\%). T-test results also showed significant differences between genders for steps taken during the school day at the 0.01 alpha level with boys averaging 7,404 steps and girls averaging 6,622 steps. No significant differences were found between genders when comparing calories expended with boys averaging 1,767 calories and girls averaging 1,481 calories. Results for all categories of physical activity (MVPA, steps, calories, vigorous + minutes, vigorous minutes, moderate minutes, easy minutes and very easy minutes) can be seen in Table 2 .

Students averaged more activity in all three major categories during the fall semester when compared with the spring semester. T-test results when comparing both semesters showed 
significant differences at the 0.01 alpha level for both MVPA and steps taken, again, calories expended did not show any significant differences.

The reliability analysis using Cronbach's alpha suggested that at least four days of measurement were needed to achieve an alpha of 0.80 for both steps $(\alpha=0.825,95 \%$ CI $[0.777$ 0.865]) and MVPA $(\alpha=0.839,95 \%$ CI [0.795-0.87]) during spring collection. During the fall semester, at least four days were also necessary to achieve a reliability of 0.80 in steps $(\alpha=$ 0.803, 95\% CI [0.751-0.846]) and MVPA $(\alpha=0.811,95 \%$ CI [0.761-0.852]). However, fall five-day activity patterns did exhibit greater variability than four-day activity patterns in both steps $(\alpha=0.784,95 \%$ CI [0.730-0.830]) and MVPA $(\alpha=0.794,95 \%$ CI [0.742-0.838]). Alpha and confidence interval results for 2 days, 3 days, 4 days and 5 days of measurement are reported in Table 3.

\section{Discussion}

The data collected in this study, shows that boys, during the fall collection period attained 47.5 minutes of MPVA during the school day, and 44.6 minutes during the spring collection. This determined that boys reached $79 \%$ of their 60 minute goal during the fall semester and $74 \%$ of their goal during the spring semester. Girls, during the fall collection reached an average of 41.5 minutes of MVPA during the school day, and 36.3 minutes during the spring collection period. These findings concluded that girls reached $69 \%$ of their daily goal in the fall semester and $60 \%$ of their goal in the spring semester. According to the American College of Sports Medicine, children of this age should be reaching at least 12,000 steps per day (Colley, 2011). Boys averaged 7,800 and 7,404 steps during the school day for the fall and spring semester respectively, accounting for $65 \%$ and $61 \%$ of their daily goal. Girls averaged 7,188 and 6,622 steps during the school day for the fall and spring semester respectively, accounting for $59 \%$ and 
$55 \%$ of their daily goal. With U.S. children spending almost half of their waking hours inschool, these results are promising. A strong emphasis still needs to be placed on physical activity outside of school in order for the students to reach their daily activity recommendation. It should be expected that students get at least half of their daily requirements during the school day, at least 30 minutes of MVPA and at least 6,000 steps. The results of this study indicate that children are achieving more than half of their daily requirements in-school, more specifically boys are exceeding those expected minutes of school based activity and steps, with the girls still remaining above 30 minutes of MVPA and over 6,000 steps.

These results are similar from those found by Zook et al. (2015) in which they observed daily in-school activity of 102 fifth grade students. They found that boys averaged 36.27 minutes of MVPA/school day and 6,519 steps/day while girls only averaged 27.01 minutes of MVPA/school day and 5,755 steps/day. In their research they found that boys engaged in more physical activity per day than girls across both MVPA and steps. However, when comparing these two studies, a significant difference must be discussed. The overall activity observed by Zook et al. (2015) was much lower than that found in the present study, with girls achieving less than 50\% of their daily goal in both MVPA and steps. Zook et al. (2015) did not measure during two semesters, and therefore had a smaller sample size and was confined to only one time during the school year. This information is important because it further displays the fact that fifth grade boys, on average, take part in greater amounts of physical activity during the course of a school day. From this, considerations should be taken when planning certain activities throughout the day that attempt to evoke more activity from the girls.

Results of this study show similar findings to those by Mota et al. (2003) who observed the activity patterns throughout the entirety of the day of 84 children from 8-15 years old. They 
discovered that throughout the entire day, boys accumulated greater amounts of MVPA than girls, which coincides with the results of our study. However, their study examined activity outside of school as well and even though boys obtained more minutes of MVPA during the entire day, girls reached a higher average of MVPA during the school day. The girls tended to be more active during school periods, while the boys were more active after school (Mota et al., 2003).

A study done by Belcher et al. (2010) examined NHANES data from 3,106 children ages 6-19 years old found that girls reached significantly lower levels of MVPA than boys. Our findings were similar with these results as well. Again, this information furthers the notion that educators should incorporate more physical activity opportunities for girls throughout the school day. Also, based on the findings by Mota et al. (2003), girls should also be engaging in more physical activities after school as well. The more opportunities that girls have and the more comfortable they can feel while participating in physical activity, the more likely they will be to habitually engage in such activities, without thinking of it as mandatory exercise or physical activity.

Our study found significant differences in MVPA and step for both boys and girls in the fall and spring collections. Across higher intensities of physical activity, boys obtained higher averages than girls. Vigorous + , vigorous, moderate and easy minutes were all on average higher for boys than for girls. The greater amount of time switched at the very easy intensity in which girls averaged almost 5 more minutes of very easy time per day than boys. According to these results along with those previously discussed, it is evident that boys are spending more times at greater intensities of exercise than girls. This can be explained by the nature of how boys interact with one another. A lot of boys' social involvements and play consists of sport and 
physical activity; it is only natural for them to maintain that involvement during the school day. On the other hand, with girls being less interested in sport and activity, they may find less opportunity to be active during the school day. Our findings indicate a slight decline in physical activity levels from the fall to the spring semester. The study took place in Midwestern community; therefore a great change in climate occurs with season's change. Fall activity was measured during the September and October months, in which it is typically still warm and optimal for outdoor activities. Agendas and class schedules could have been altered and increased outdoor physical activity could have been implemented throughout the course of fall measurement. The spring activity measurement took place during the January and February months. Although it is the spring semester, early spring time in the Midwest is not very suitable for in-school outdoor activities. This could explain the decline in activity levels between semesters. The decline was consistent across all measurements of physical activity. The trend of boys maintaining higher levels of activity remained constant however between both collection periods.

Schools implementing Comprehensive School Physical Activity Programs (CSPAP) aim to increase in school physical activity habits by providing a variety of school-based physical activities to enable all students to participate in 60 minutes of moderate-to-vigorous physical activity each day. A CSPAP reflects strong coordination and synergy across all of the components: quality physical education as the foundation, physical activity before, during, and after school, staff involvement, and family and community engagement. Schools should consider using CSPAPs in order to develop structured physical activity programs to help ensure that their students are achieving proper levels of in- school physical activity. 
The results of the secondary aim of this study showed that 4 days of monitor wear time is optimal for attaining an accurate mean measurement of physical activity which is consistent with the findings in the majority of the literature. A study done by Trost et al. (2000) in which they studied 381 students for seven consecutive days, indicates that children in grades 1-6 exhibit less day to day variability in MVPA behavior and that 4 to 5 days of monitoring are necessary to achieve a reliable mean measurement. It should also be noted from the study done by Trost et al. (2000) that older children exhibit greater variability in their day to day activity and require an 8-9 day monitoring period for a reliable measurement. Our study did not measure the reliability of different days of the week; however, children display much more activity during the weekends than they do during the weekday while adolescents participate in significantly less physical activity on the weekends (Trost et al., 2000). This data can be related to our study and indicate that even though the children may not be achieving their daily goals for activity during school, they may be more likely to reach their daily goals on the weekends in the same time period as a normal school day.

Tudor-Locke et al. (2004) examined activity patterns for 90 adult participants for seven days straight in order to determine how many days as well as which days of the week are most optimal for predicting activity levels in adults. This study found evidence inconsistent with ours, indicating that any three days of the week, except for Sunday, are sufficient enough to predict physical activity trends in adults. This study is slightly unrelated to ours because they examined only adult physical activity. Adult physical activity trends tend to be less variable than those of children which can explain why fewer days are required for adults than for children. When attempting to accurately measure average activity patterns amongst children, especially in-school physical activity, researchers should strive for obtaining at least 4 days of data. 
When discussing our fall measurement, this data is inconsistent with most previous research on the topic in that our study shows that fall MVPA and fall steps show greater variability during the 5 day average than the 4 day average. Research done by Trost et al. (2000) shows that as the amount of days of measurement increases, the reliability of the measurement also increases. This is not displayed in our study, perhaps due to the fact that school different schools followed different schedules and activity patterns were not consistent across all four schools.

The inconsistent findings in this study and the results from previous studies assessing the amount of days necessary for a reliable measurement warrants the need for further research on the topic of monitoring in-school physical activity measurements in elementary school children.

\section{Conclusions}

The present study shows that both boys and girls achieved higher levels of MVPA during the fall semester than the spring semester, however boys received substantially higher amounts of MVPA than girls during both semesters. It can be assumed that boys participated at a higher intensity in many of the daily physical activities and therefore were able to reach higher levels of MVPA during the school day. Based on the percentages of MVPA achieved during in-school hours, it is most likely that these students, both males and females, are getting adequate physical activity (60 minutes MVPA) during the entirety of the day, provided that they are maintaining activity some point in their day outside of school.

This study also suggests that at least four days of in-school physical activity measurement are required to achieve an accurate interpretation of the average daily habits of fifth grade students. Research that aims to examine in-school physical activity patterns in elementary school students, specifically fifth graders, should obtain at least 4 days of quality measurement. 
However, the inconsistent result of the reliability of five days of measurement during fall collection with results from previous studies warrants further research on this topic to fully determine how many days are necessary to receive a true average of physical activity. 
Table 1

Characteristics of Subjects (Means \pm S.D.)

\begin{tabular}{ccccc}
\hline & Age & Height (in.) & Weight (lb.) & BMI \\
\hline Fall Total $(\mathbf{N = 1 8 6 )}$ & $\mathbf{1 0 . 6} \pm \mathbf{0 . 5 0}$ & $\mathbf{5 7 . 7} \pm \mathbf{3 . 6 2}$ & $\mathbf{9 1 . 6} \pm \mathbf{2 5 . 5 8}$ & $\mathbf{1 9 . 2} \pm \mathbf{4 . 3 2}$ \\
Boys $(\mathrm{n}=92)$ & $10.7 \pm 0.48$ & $57.7 \pm 3.63$ & $92.4 \pm 26.67$ & $19.3 \pm 4.35$ \\
Girls $(\mathrm{n}=94)$ & $10.6 \pm 0.51$ & $57.7 \pm 3.62$ & $90.9 \pm 24.5$ & $19.1 \pm 4.32$ \\
\hline Spring Total $(\mathbf{N = 1 7 9 )}$ & $\mathbf{1 0 . 9 6} \pm \mathbf{0 . 3 8}$ & $\mathbf{5 7 . 6 5} \pm \mathbf{3 . 5 9}$ & $\mathbf{9 0 . 7 2} \pm \mathbf{2 3 . 9 7}$ & $\mathbf{1 9 . 0 7} \pm \mathbf{4 . 1 3}$ \\
Boys (n=88) & $11.03 \pm 0.41$ & $58 \pm 3.92$ & $92.75 \pm 25.51$ & $19.25 \pm 4.21$ \\
Girls $(\mathrm{n}=91)$ & $10.89 \pm 0.34$ & $57.31 \pm 3.21$ & $88.75 \pm 22.34$ & $18.89 \pm 4.07$ \\
\hline
\end{tabular}




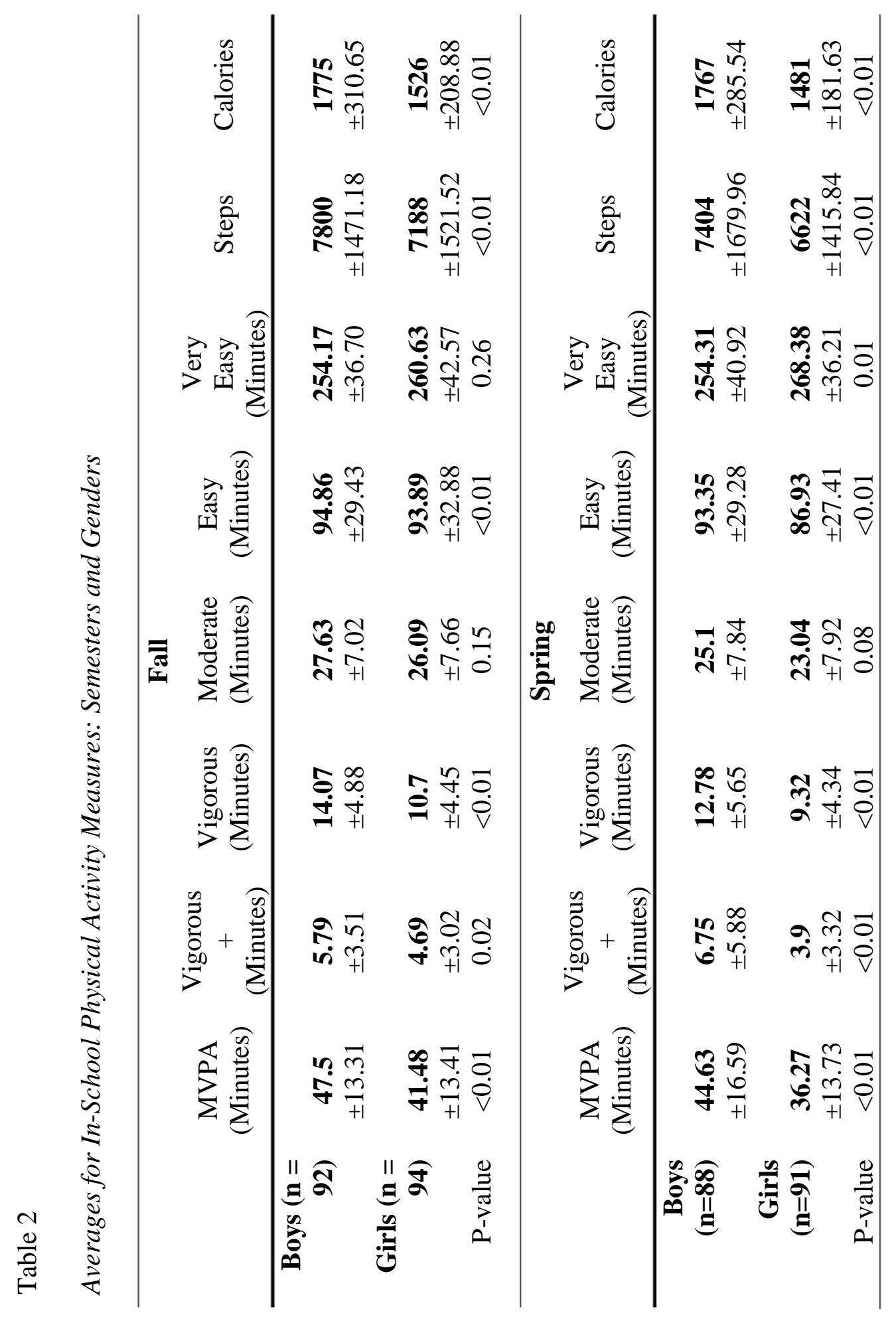


Table 3

Intraclass Correlation Coefficient Tables for MVPA and Steps

\begin{tabular}{lcccc}
\hline & \multicolumn{4}{c}{ Correlation Coefficient $(95 \%$ Confidence Intervals) } \\
\cline { 3 - 5 } & 5 Days & 4 Days & 3 Days & 2 Days \\
\hline Fall MVPA & $.795(.742-.838)$ & $.811(.761-.852)$ & $.786(.726-.835)$ & $.739(.650-.805)$ \\
Fall Steps & $.784(.730-.830)$ & $.803(.751-.846)$ & $.772(.707-.824)$ & $.747(.660-.811)$ \\
Spring MVPA & $.866(.831-.896)$ & $.839(.795-.875)$ & $.771(.704-.826)$ & $.719(.618-.793)$ \\
Spring Steps & $.850(.810-.883)$ & $.825(.777-.865)$ & $.782(.717-.833)$ & $.765(.681-.827)$ \\
\hline
\end{tabular}

Table 4

Differences Between Semesters: MVPA and Steps (Genders Combined)

\begin{tabular}{ccccc}
\hline & Fall & Spring & Mean Difference & P - Value \\
\hline MVPA & & & & \\
Minutes & 44.46 & 40.38 & 4.08 & $<0.01$ \\
& \pm 13.81 & \pm 15.79 & & $<0.01$ \\
\hline Steps & 7491 & 7006 & 485 & \\
& \pm 1582.36 & \pm 1640.09 & & \\
\hline
\end{tabular}




\section{References}

Adkins, M., Bice, M., Bartee, T., \& Heelan, K. (2015). Increasing physical activity during the school day through physical activity classes: Implications for physical educators. The Physical Educator, 72(2), 173-178.

Belcher, B. R., Berrigan, D., Dodd, K. W., Emken, A., Chou, C., \& Spruijt-Metz, D. (2010). Physical activity in US youth: Effect of Race/Ethnicity, age, gender, and weight status. Medicine \& Science in Sport \& Exercise, 42(12), 2211-2218.

Bohr, A. D., Brown, D. D., Laurson, K. R., Smith, P. J. K., \& Bass, R. W. (2012). Relationship between socioeconomic status and physical fitness in junior high students. Journal of School Health, 83(8), 542-459.

Bunketorp Kal, L., Malmgren, H., Olsson, E., Linden, T., \& Nilsson, M. (2015). Effects of a curricular physical activity intervention on Children's school performance, wellness, and brain development. Journal of School Health, 85(10), 704-713.

Carlson, J., Engelberg, J., Cain, K. L., Conway, T. L., Mignano, A. M., Bonilla, E., Sallis, J. F. (2015). Implementing classroom physical activity breaks: Associations with student physical activity and classroom behavior. Preventative Medicine, 81, 67-75.

Carlson, J., Sallis, J. F., Norman, G., McKenzie Thomas, Kerr, J., Arrendondo, E. M., Saelens, B. E. (2013). Elementary school practices and children's objectively measured physical activity during school. Preventative Medicine, 57, 591-598.

Caspersen, C. J., Pereira, M. A., \& Curran, K. M. (2000). Changes in physical activity patterns in the United States, by sex and cross-sectional age. Medicine \& Science in Sport \& Exercise, 32(9), 1601-1611.

Childhood obesity: Causes and consequences. (2016). Center for Disease Control and Prevention

Colley, R. (2011). Children's daily step count can be used to gauge physical activity goals. Medicine \& Science in Sport \& Exercise

Dowda, M., Taverno Ross, S. E., McIver, Kerry L., Dishman, R. K., \& Pate, R. P. (2017). Physical activity and changes in adiposity in the transition from elementary to middle school. Childhood Obesity, 13(1) 1-12.

Fu, Y., Burns, R., Brusseau, T., \& Hannon, J. (2016). Comprehensive school physical activity programming and activity enjoyment. American Journal of Health Behavior, 40(4), 496502.

Haskell, W. L., Macera, C. A., Pate, R. P., Powell, K. E., Blair, S. N., Franklin, B. A., Bauman, A. (2007). Physical activity and public health updated recommendation for adults from the American college of sports medicine and the American heart association; Medicine \& Science in Sport \& Exercise, 39, 1-9. 
Haskell, W. L., \& Nelson, M. E. (2008). Physical activity guidelines advisory committee report, 2008. U.S. Department of Health and Human Services

Kwon, S., Mason, M., \& Welch, S. (2014). Physical activity of fifth to sixth graders during school hours according to school Race/Ethnicity: Suburban cook county, Illinois. Journal of School Health, 85(6), 382-390.

Mota, J., Santos, P., Guerra, S., Ribeiro, J., \& Duarte, J. (2003). Patterns of daily physical activity during school days in children and adolescents. American Journal of Human Biology, 547(53) 418-423.

Ogden, C. L., Carroll, M. D., Fryar, C. D., \& Flegal, K. M. (2015). Prevalence of obesity among adults and youth: United states, 2011-2014. U.S. Department of Health and Human Services, 1(219), 1-5.

Physical activity and health: The benefits of physical activity. (2015). Center for Disease Control and Prevention.

Physical activity in youth and adolescents. (2015). The American College of Sports Medicine.

Tremblay, M. S., Wyatt Inman, J., Willms, \& J. Douglas. (2000). The relationship between physical activity, self-esteem, and academic achievement in 12-year-old children. Pediatric Exercise Science, 12, 312-320.

Trost, S. G., Pate, R. P., Freedson, P. S., Sallis, J. F., \& Taylor, W. C. (2000). Using objective physical activity measures with youth: How many days of monitoring are needed? Medicine \& Science in Sport \& Exercise, 32(2), 426-430.

Trost, S. G., Pate, R. P., Sallis, J. F., Freedson, P. S., Taylor, W. C., Downda, M., \& Sirard, J. (2001). Age and gender differences in objectively measured physical activity in youth. Medicine \& Science in Sport \& Exercise, 34(2), 350-351.

Tudor-Locke, C., Burkett, L., Reis, J. P., Ainsworth, B. E., Macera, C. A., \& Wilson, D. K. (2004). How many days of pedometer monitoring predict weekly physical activity in adults? Preventative Medicine, 40(1), 293-300.

Zook, K. A., Brown, D. D., Laurson, K. R., \& Williams, S. M. (2015). Contribution of in school physical activity to daily activity patterns in 5th grade children (Master of Science). 


\section{CHAPTER II: EXTENDED REVIEW OF THE LITERATURE}

\section{Specific Research}

Physical activity is a key factor of health and wellness for people of all ages in the United States. Regular, habitual physical activity is one of the most important things an individual can do for their health. According to the CDC it can: control weight, reduce cardiovascular disease risk, reduce risk of type 2 diabetes, reduce risk of some cancers, improve mental health and mood, improves the ability to perform daily activities and increases the chances of living longer. Physical activity is defined as any bodily movement produced by the contraction of skeletal muscle that increases energy expenditure above a basal level. Physical activity generally refers to the subset of physical activity that enhances health, while exercise is defined as a subcategory of physical activity that is planned, structured, repetitive, and purposive in the sense that the improvement or maintenance of one or more components of physical fitness is the objective (Hahn et al., 1990). For individuals of all ages, physical activity and exercise are essential on a daily basis in order to maintain overall health and wellness as well as the prevention of both acute and chronic diseases. Medical advancements in today's society have significantly reduced the number of infectious diseases and early life mortality resulting in record average life spans for much of the human population. However, taking the place of these infectious diseases is a widespread of chronic diseases. The CDC Website states, "Chronic diseases — such as heart disease, cancer, and diabetes — are the leading causes of death and disability in the United States. Chronic diseases account for $70 \%$ of all deaths in the U.S., which is 1.7 million each year. The CDC also states that, "Chronic diseases such as heart disease, stroke, cancer, diabetes, and arthritis are among the most common, costly, and preventable of all health problems in the U.S.". Prevention starts with physical activity and is necessary to start at a young age. If children are 
exposed to increased levels of physical activity when they are younger, they are more likely to maintain those levels of activity throughout their lives.

Research relating the benefits of physical activity as well as the risk of physical inactivity has increased substantially over the past 50 years. In 1953, Jeremiah Morris conducted a study comparing physical activity of bus drivers, who are sedentary in their occupations, and bus conductors, who were constantly moving up and down double decker buses to collect riders' fares in London. Morris et al. found that physically active conductors had a $30 \%$ lower incidence rate of coronary heart disease (CHD) than the physically inactive bus drivers. They also found that even the physically active conductors who did developed CHD with age were better off, presenting with less severe disease and lower fatality rates than the inactive bus drivers. This report was substantial in the physical activity epidemiology field due to its relation of inactivity and increased morbidity and mortality (Blair et al., 2010). As scientists continued examining the relationship of physical inactivity and health, in 1965, a book titled "The Physiology and Pathology of Bed Rest" was written by Norman L. Browse. In the book, it states that pathologies of prolonged bed rest consist of: postural hypotension, tachycardia, kidney stones, loss of skeletal muscle mass, and weakness in antigravity muscles, pressure ulcers, osteoporosis, deep vein thrombosis and pneumonia. During the 1960's, Saltin et al. completed the Dallas bed rest study in which they examined 5 healthy college age males for 20 days of continuous bed rest. They found that on average: VO2 max declined by $28 \%$, ventricular volume declined by $11 \%$, maximal cardiac output declined by $26 \%$ and maximal stroke volume declined by $29 \%$ from pre to post testing. Although it is not often that individuals are in a state of bed rest, it simply shows the extreme negative effects of physical inactivity and how quickly they can occur. Advancements in technology as well as increased need and interest in the topic 
of physical activity related to health has driven a large amount of current research. Altogether, the historical and current research provides substantial evidence that physical inactivity can cause decreases in capacities of functional systems, leading to premature disease and potentially death in humans.

In recent decades, the prevalence of obesity has increased dramatically in the United States. It has nearly tripled among children as well as doubled among adults (Benjamin, 2010). This epidemic can be noted as the result of changes in our environments and behaviors. High calorie, good tasting, and inexpensive foods are now more widely available and excessively advertised. Not to mention, portion sizes have significantly increased and individuals are eating more frequently. Also, car depended designs of communities makes it harder to promote physical activity as a mode of transportation to work, school or to go shopping. On top of all these changes, many schools across the nation have cut back or eliminated recess and physical education programs all together (Benjamin, 2010).

A 2010 report by the Surgeon General stated that the prevalence of obesity changed relatively little during the 1960s and 1970s but there was a sharp increase over the next decades. In 1980 the obesity prevalence in the adult population was $13.4 \%$ and by 2008 the obesity prevalence in the US was up to $34.3 \%$, with a childhood prevalence of $17 \%$ (Benjamin, 2010). Obesity is typically defined as excess body fat. Body fat is difficult to measure, especially in large populations, therefore body mass index (BMI) is typically used to measure total body fatness. BMI is calculated as weight in kilograms divided by height in meters squared. Adults with a high BMI are at an increased risk for various diseases and children who have a high BMI are likely to have relatively high levels of body fatness (Freedman et al., 2009). 
A study by Ogden et al. (2015) looked at 9120 individuals in an NHANES data set to analyze obesity prevalence in the United States from 2011-2012. They determined that $16.9 \%$ of youth and $34.9 \%$ of adults were obese. The data suggested that there were no significant changes when compared with data from 2003-2004. This study ultimately found that "there have been no significant changes in obesity prevalence in youth or adults between 2003-2004 and 2011-2012. Obesity prevalence remains high and thus it is important to continue surveillance". Although this data does not show that obesity levels are continuing to increase, it does show that obesity levels are still at a high level and have been at a high level for many years. It is important to make steps in decreasing obesity levels in both youth and adults by increasing physical activity levels in people of all ages.

The American College of Sports Medicine issued "Physical Activity and Public Health Updated Recommendation for Adults” in 2007 (Haskell, 2008). The physical activity recommendations apply to healthy adults between the ages of 18-65 years old. To promote and maintain health, all healthy adults need moderate intensity aerobic activity for a minimum of 30 minutes on five days each week or vigorous intensity aerobic activity for a minimum of 20 minutes on 3 days each week, combinations can be performed to meet the recommendation. Adults should also be participating in muscle strengthening exercise as well. Adults will benefit from performing such exercises at a minimum of two days each week, it is recommended that 810 exercises be performed on two or more times per week. Individuals who wish to promote and improve their fitness or further reduce their risk for premature chronic health conditions and mortality related to physical inactivity should exceed those recommendations (Haskell et al., 2008). 
In order to achieve and maintain a greater health status as an adult, it is vital that physical activity and exercise be a large part of a child's day. Daily physical activity monitoring in youth has become very widely studied and analyzed not only in the field of epidemiology, but the medical field as a whole due to its relation to preventing chronic health issues later in life.

Adolescents and young adults, can benefit from any amount of physical activity. That physical activity does not need to be extremely strenuous to be beneficial. Moderate amounts of physical activity can be accumulated throughout the day. According to the CDC, greater amounts of physical activity are even more beneficial, up to a point. Excessive amounts of physical activity can lead to injuries, menstrual abnormalities and bone weakening. The Centers for Disease Control and Prevention reports that nearly half of American youths aged 12-21 years old are not vigorously active on a regular basis. About 14 percent of young people report no recent physical activity. Inactivity is more common among females (14\%) than males (7\%) and among black females (21\%) than white females (12\%). They also report that as children get older, inactivity levels decline. Only $19 \%$ of all high school students are physically active for 20 minutes of more, five days per week in physical education classes, and daily enrollment in physical education classes has been on a steady decline. With these findings, well designed school based interventions directed at increasing physical activity during the school day have been created and are often shown to be effective.

Similar findings are reported by the American College of Sports Medicine. ACSM states that only $27 \%$ of students accumulate 60 minutes of physical activity daily, $52 \%$ participate in muscle strengthening activities, $29 \%$ attend daily physical education class while $41 \%$ of students play video games for 3 or more hours per day and $32 \%$ of students watch television 3 or more hours per day. Regular participation in different types of activity is essential for a child's healthy 
growth and development. The American College of Sports Medicine Youth Physical Activity Guidelines (2015) state that: "Children and Adolescents should accumulate a minimum of 60 minutes of physical activity daily as part of transportation, physical education, sport, free play, and planned exercise. The activities should be a combination of moderate and vigorous intensity. Moderate intensity can be defined as activity that increases breathing, sweating and heart rate and vigorous intensity activity substantially increases breathing, sweating and heart rate".

Along with the ACSM recommended activity total, a comprehensive review of literature commissioned by the Public Health Agency of Canada (PHAC) was performed by Tudor-Locke et al. (2004) to determine how many steps per day are enough for children in order to meet the same requirement for 60 minutes of daily physical activity. Their results show that across studies, 60 minutes of MVPA in elementary school children appears to be achieved, on average, within a total volume of 13,000 to 15,000 steps per day in boys and 11,000 to 12,000 steps per day in girls. For adolescents (both boys and girls), 10,000 to 11,700 may be associated with 60 minutes of MVPA. Their research shows that there is not a universal amount of steps across all ages of children. However, it suggests that as children get older, the amount of steps required to achieve their daily activity goal does decrease. From these findings, the researchers suggest that children within these age classifications attempt to achieve these amount of steps throughout the day in order to achieve their daily activity goal.

A secondary study done by Colley et al. (2011) provides similar findings, however the authors suggest that children should have a goal to achieve 12,000 steps per day to maintain a healthy level of physical activity. The researchers conducted a correlation analysis between daily steps taken and minutes of MVPA in both children and teens. At 12,000 steps, they 
determined the subjects had reached the equivalent of 60 minutes of MVPA. These results are similar to those of Tudor-Locke et al. (2011) however, this study does not break down the children by gender or age. They state 12,000 steps should be used as a target number for all children and that any amount of steps above that number should be considered as additional beneficial activity.

While the guidelines and recommendations exist suggesting necessary amounts of physical activity in youth, many studies show that children are not getting the required levels of activity needed to earn health and wellness benefits. A study done in 2011 by Kwon et al. (2014) observed activity levels of 591 fifth and sixth grade students in 14 SCC public schools. The students wore the monitors for 4 consecutive school days. The boys, on average, obtained 9 minutes per day more MVPA than girls. However, the results also suggest that the boys mean MVPA was only 19.9 minutes/day, based on the 6.5 hours of monitor wear time. Only 1 boy in the entire sample participated in greater than 60 minutes of MVPA during the school day. The girls obtained an average MVPA level of 11.1 minutes per day (Kwon et al., 2014). The work done by Kwon et al. also examined activity levels based on race/ethnicity of the schools. On average, Non-Hispanic White boys participated in the most daily in-school MVPA with 26.9 minutes and Hispanic girls participating in the least amount of daily in-school MVPA with only 7.3 minutes. This study produced results showing that the students were not getting half of their daily recommended activity during the school day based on the guidelines set forth by the ACSM as well as Tudor-Locke et al. (2011).

Research done by Trost et al. (2001) observed activity levels form 185 male and 190 female students for 7 consecutive days, both in-school and out of school, to examine age and gender related trends in activity. The study found that daily moderate vigorous physical activity 
(MVPA) and vigorous physical activity (VPA) exhibited a significant inverse relationship with grade level, with the largest differences occurring between grades 1-3 and 4-6. Boys were more active than girls; however, for overall physical activity, the magnitudes of the gender differences were small. Unlike the previously discussed study by Kwon et al. (2014) this study observed physical activity of children throughout the entirety of the day. MVPA levels declined steadily as children aged. Children, boys and girls, in grades 1-3 averaged 200 minutes of MPVA/day, children in grades 4-6 averaged 110 minutes of MVPA/day, children in grades 7-9 averaged 70 minutes of MVPA/day and children in grades 10-12 averaged 50 minutes of MVPA/day. According to these results, these students are all exceeding their ACSM recommended levels of MPVA. It should be noted however, that this study took place both in-school and out of school, therefore it cannot be determined how much in-school physical activity contributed to the daily activity levels of these students. What can be determined, however, is that similar to the findings by Kwon et al. (2014) boys are achieving significantly higher amounts of MVPA during the day than girls, both in-school and out of school across all age levels.

A study done by Mota et al. (2003) examined MVPA levels of 84 subjects, ages 8-15 years old. They observed the activity levels of both in-school and out of school activity levels during school days (week days). Interestingly, they looked at the activity to determine differences in activity patterns between genders at different times during the day. Similarly to previous studies, these results showed that boys participated in greater amount of MVPA than girls. Girls showed higher percent of time engaged in MVPA during the morning and early afternoon periods of the day, while boys' percent of time engaged in MVPA is higher at late afternoon and evening periods (Mota et al., 2003). Conversely, this research, shows different results than those of Kwon et al. (2014). This study shows that girls participated in greater 
amounts of MVPA during the school day yet, boys participate in greater MVPA outside of school, in the afternoon periods.

A study done by Belcher et al. (2010) set out to describe physical activity levels by race/ethnicity, age, gender, and weight status. They looked at cross-sectional data from the 2003-2004 and 2005-2006 National Health and Nutrition Examination Survey (NHANES). 3,106 youth aged 6-19 years old with at least four 10 hour days of physical activity measured by accelerometry were included in the data set. Results of this analysis indicate that the 6 to 11 year old group recorded 88 minutes of MVPA per day, whereas youth in the 12 to 15 year old group and 16 to 19 year old groups recorded 33 and 26 minutes of MVPA per day, respectively. The youngest group also spent significantly much less time in the sedentary behavior minutes and more time in the moderate physical activity minutes as well as the vigorous physical activity minutes. Non-Hispanic black 16 to 19 year olds were the most inactive race/ethnic group, spending, on average, 520 minutes per day in sedentary behavior. Females spent fewer minutes in MVPA than males and 20 more minutes per day in sedentary behavior than males. Compared to obese youth, normal weight youth spent significantly more time in the moderate activity, vigorous activity and MVPA categories of activity (Mokdad et al., 2004). Across three racial/ethnic groups (Non-Hispanic White, Non-Hispanic Black and Mexican American), as BMI classification (normal weight, overweight, obese) increased, mean minutes of MVPA decreased with females of all ethnicities participating in greater amounts of sedentary behavior and significantly less time in MVPA behavior than males (Belcher et al., 2010). This study relates the data to the 2008 Physical Activity Guidelines Advisory Committee Report done by the U.S. Department of Health and Human Services. The results of this study indicate that $41.4 \%$ met the recommendations. Females were less likely to adhere to the guidelines than males. For males, 
those most likely to meet the guidelines were non-Hispanic black, aged 6 to 11 years old, and of normal weight. The authors stated that "Genetic predisposition to obesity, socioeconomic status, and cultural differences in behavior may play a role in the race/ethnic differences found in this sample" (Belcher et al., 2010).

Continued research by Taverno Ross et al. (2016) examine 495 elementary students who participated in the Transitions and Activity Changes in Kids (TRACK) Study. Physical activity was assessed objectively as well as by self-report. Children, parents, and school administrators completed surveys to assess related factors. The study produced a three class model based on physical activity (PA) and sedentary behavior (SB). Class 1 was low PA and high SB, Class 2 was moderate PA, high SB, and Class 3 was high PA. Among boys, Class 1 accounted for the majority of the sample (70.6\%), Class 2 included $15.4 \%$ of the sample and Class 3 accounted for $14.0 \%$ of the sample. Similar to the boys, Class 1 was also the largest group accounting for $54.4 \%$ of girls, Class 2 included $32.8 \%$ of the sample and Class 3, which comprised another $12.8 \%$ of the sample (Taverno Ross et al., 2016). Similar to previous findings, a larger majority of boys participated in greater amounts of activity than girls. This study also observed how the activity patterns trended throughout grade levels. Activity patterns were observed across grades 5-7. Boys in Classes 1 and 3 showed declines in activity levels from fifth to seventh grade while boys in Class 2 did not show much change, they displayed a slight trend upwards. Girls in Classes 1 and 2 showed declines in activity levels from grades 5 to 7, with girls in Class 3 showing a significant increase in activity level from grade 6 to 7 . These results are similar to those found in previous studies in that they confirm that boys attain higher levels of physical activity than girls across elementary grade levels. These results also express that as children get older, their physical activity habits steadily decline (Taverno Ross et al., 2016). 
Further observing the trend of physical activity patterns throughout maturity and aging, Dowda et al. (2017) examined physical activity and changes in adiposity in the transition from elementary to middle school. Data was drawn from the Transitions and Activity Changes in Kids (TRACK) study, a total of 658 children from 21 elementary schools were assessed at least twice in fifth, sixth and/or seventh grade. Activity levels as well as diet, anthropometry, and maturity status were all used in the analysis. The finding supported the fact that boys had higher levels of activity than girls and that as children age their physical activity habits decrease. However, the main purpose of this research was to determine how physical activity habits effected adiposity measurements as children age. The major finding of this study was that as boys and girls transitioned from elementary to middle school, children who participated in higher levels of MVPA maintained lower levels of adiposity. The study found significant inverse relationships between MVPA and fat mass index (FMI) and percent body fat (PBF) in both boys and girls that spanned the period from fifth to seventh grade (Dowda et al., 2017). The findings in this study further express the fact the MVPA should play a large role in prevention of excessive weight gain from childhood to adolescence.

The social cognitive theory of behavior points to the importance of model learning from parents' behavior and of receiving reinforcements from significant others. "The family is a potent target for interventions to increase children's physical activity, and to prevent and improve management of childhood obesity" (Fogelholm et al., 1999). The same study by Fogelholm et al. (1999) examined differences in physical activity between normal weight and obese children, as well as parent - child associations of obesity and physical activity. A total of $152(14.5 \%)$ of the girls and $117(11.4 \%)$ of the boys were obese or markedly obese. The prevalence of marked obesity was 38 (3.6\%) among girls and 47 (4.6\%) among boys. The obese children had 
significantly lower habitual activity scores than the normal-weight children. Parents of the obese children had a higher BMI than the parents of the normal-weight children. Parental physical activity was not associated with child obesity. This findings in this study, however did not show extremely strong relationships between childhood activity patterns and obesity levels. There was a small finding in that the parent - child relationship of inactivity was stronger than that of vigorous activity. Therefore, parents who truly want to change their children's inactivity behaviors will have to pay attention to their own activity habits.

"Obesity is now the most prevalent nutritional disease of children and adolescents in the United States. Although obesity-associated morbidities occur more frequently in adults, significant consequences of obesity as well as the antecedents of adult disease occur in obese children and adolescents" (Dietz et al., 1997). Research shows that controlling weight status and fat mass in children is important for increased health status and disease prevention late in life. Increased blood lipids have a higher occurrence rate in obese children and adolescents. This consists of elevated serum low-density lipoprotein (LDL) cholesterol and triglycerides as well as lower high-density lipoprotein cholesterol levels (HDL). Central fat distribution appears to be an important controlling variable between lipid levels and obesity. Increased fatty acids produced by increased lipids in the blood as well as visceral adiposity promote hepatic triglyceride and LDL synthesis, both increasing cardiovascular disease risk. Weight reduction and fat loss are both beneficial in counteracting these risk factors (Dietz et al., 1997). Another risk factor for heart disease caused related to obesity is hypertension. However, almost $60 \%$ of the children with persistently elevated blood pressure have relative weights greater than $120 \%$ of the median for their sex, height, and age. Based on the estimated prevalence of obesity, persistently elevated blood pressure occurs approximately nine times more frequently among the obese. This 
statement along with the statistics regarding cholesterol, indicate that weight management is vital to improving health and reducing cardiovascular disease risk.

Better physical fitness as well as decreased adiposity can not only improve quality of life, but it can decrease the probability of chronic illness later in life and/or delay onset of those illnesses. A lack of exercise can be a major cause of chronic disease. The 1996 US Surgeon General's Report concluded that high cardiorespiratory fitness (CRF) decreases the risk of cardiovascular disease (CVD) mortality. High VO2max is associated with "positive health"; low VO2max is associated with "negative health." (Booth et al., 2012). Remarkably, low CRF is a stronger predictor of death than clinical variables or established risk factors, such as hypertension, smoking, and diabetes, as well as other exercise-test variables. Physical inactivity can also be linked to the occurrence of metabolic syndrome (MS). MS is currently defined as a cluster of three of five risk factors for CVD and type 2 diabetes, and include elevated triglycerides, reduced HDL-cholesterol, elevated blood pressure, and elevated fasting glucose. The fifth factor, elevated waist circumference, does not have as an effective drug treatment, the preferred treatment method is exercise. Physical activity is primary prevention for every major MS risk factor.

Risk factors for the following conditions increase with physical inactivity: coronary heart disease, type 2 diabetes, cancers (endometrial, breast, and colon), hypertension, dyslipidemia (for example, high total cholesterol or high levels of triglycerides), stroke, liver and gallbladder disease, sleep apnea and respiratory problems, osteoarthritis, and gynecological problems (abnormal menses, infertility). Physical activity and exercise is one of the largest primary prevention measurements for all of the conditions listed above. 
Although overweight and obesity in childhood are related to dyslipidemia, hyperinsulinemia, and hypertension, most studies have examined levels of these risk factors individually or have used internal cut points to classify overweight and risk factors. A study done by Myers et al. (1996) called the Bogalusa Heart Study examined activity levels of 995 children ages 9-15 years old using a 24 hour recall questionnaire. Males were found to be more physically active than females and they spent significantly more of their time in heavy physical activity. Girls were found to have a higher percentages of sedentary, light and moderate activity levels than boys. Interestingly, and in agreement with research done by Dowda et al. (2017) both fifth and sixth graders has significantly smaller percent of sedentary time than eighth graders, showing that activity levels decline as children get older. Children in seventh grade had a higher percentage of moderate activity than eighth graders as well (Myers et al., 1996). There was also an increase in minutes of selected sedentary activity after school with grade; the differences between 5th graders and 7th and 8th graders were significant. As children got older, they chose more sedentary activities after school. As grade increased, children spent less time game playing, ball playing, jumping rope, and doing gymnastics. The Bogalusa Heart Study also examined types of activities that were most popular among the children. More girls than boys reported walking (84 vs. 72\%) whereas more boys than girls reported running (64 vs. 54\%). Boys also ran and walked/ran for more minutes, strengthening the fact that boys spend more time in the heavier physical activity categories than girls. Based off of the activity data collected during this study, the researchers were able to compare physical and sedentary activity levels to risk factors for diseases. Children below the median sedentary time had significantly smaller skinfold site measurements than those children that were above the median time of sedentary activity, showing a relationship between body composition and physical activity level. Also, the 
study found that diastolic blood pressure was highest in children in the lowest physical activity quartile and decreased linearly for those in the highest activity quartile (Myers et al., 1996). The higher triglyceride levels were found among those in the $60-70^{\text {th }}$ percentiles and lowest levels among those in the higher quartile, therefore, this study did not find that optimal triglyceride levels related to higher levels of physical activity.

With substantial research done showing the benefits of physical activity and exercise in children as well as the relationship between inactivity and increased risk factors, many schools are using various programs, implementations, technologies and many other methods to increase physical activity in-schools, not only during physical education classes and recess, but in their classrooms as well. In 2013, less than half of high school students attended physical education classes in an average week. The percentage of high school students who attended physical education classes daily decreased from $42 \%$ in 1991 to $25 \%$ in 1995 and has remained stable into 2013 at $29 \%$. In $2013,42 \%$ of 9 th-grade students but only $20 \%$ of 12 th-grade students attended physical education class daily. With this information, it is important that children are getting their physical activity in elsewhere throughout the day. Since children spend almost half of their waking hours of the day at school, it is vital that they get at least half of their recommended daily activity in-school. Physical activity promotion during the school day is highly recommended.

A study by Carlson et al. (2013) used surveys regarding multiple physical activity "practices" that students were exposed to during a school day, using NIK and MOVE data sets. The practices assessed included whether the school had a physical education teacher, training was provided to increase MVPA in PE, recess was supervised by a classroom teacher, organized activities (e.g., walking programs, games) were provided during recess, classroom teachers were provided training on classroom physical activity breaks, and classroom teachers implemented 
classroom physical activity breaks. Informants also reported the number of minutes/physical education lesson and 8) number of lessons/week of physical education, 9) number of students/physical education lesson, average length of recess periods, and average number of students/supervisor during recess (Carlson et al., 2013). Children at schools that had 4 of the 5 top practices obtained twice as many min/day of physical activity during school than children at schools that had only 0 or 1 of the 5 practices. The relationship between the various school practices and children's physical activity levels suggest that schools need to adopt multiple physical activity practices. However, having a physical education teacher and providing at least $100 \mathrm{~min} /$ week of physical education stood out as important single practices in this study.

Similarly, Carlson et al. (2015) performed another study in which they examined solely the implementation of in class physical activity breaks and their effects on overall in-school MVPA levels in students. Students wore activity monitors throughout the school day. The researchers also administered surveys to teachers, asking questions regarding daily physical activity habits amongst their students, the goals of the surveys were to see what types of activity breaks were being used, how many breaks were implemented, and how many total minutes of activity breaks were used. Students of teachers who reported being encouraged to hold physical activity breaks had 1.84 more minutes per day of MVPA during school than students of teachers not reporting encouragement. Students of teachers who reported ever holding activity breaks had 3.14 more minutes per day of MVPA during school and were $75 \%$ more likely to have met the 30 minutes per day guideline for MVPA during school. In classrooms where teachers reported never holding activity breaks, an average of $24.2 \%$ of students met the 30 -minute guideline versus $35.8 \%$ in classrooms where teachers recorded holding activity breaks. From this study, the researchers concluded "Implementing classroom physical activity breaks can improve student 
physical activity during school and behavior in the classroom. Comprehensive school physical activity programs that include classroom based activity are likely needed to meet the $30 \mathrm{~min} /$ day school physical activity guideline" (Carlson et al., 2015). In agreement with the previous study done by Carlson et al. (2013) these findings indicate that the more exposure children have to physical activity throughout the school day, the more likely they are to meet their recommended levels.

Across the United States, physical education classes and time spent in those classes are being diminished significantly. Nevertheless, it is important for schools to find alternative ways to provide students with proper amounts of physical activity. The mission to increase PA of children can be made possible with the creativity to modify the school schedule and incorporate physical activity breaks throughout the day. Research done by Adkins et al. (2015) found that if teachers gave 1 to 2 minute activity breaks during core classes on days when students did not participate in physical education classes, the students were "more attentive in class" and "constantly moved" throughout the entire break. These breaks also helped contribute more to their overall MVPA as well.

Not only is the necessity to obtain greater amounts of activity in a school day necessary, but also the education on the importance of exercise and structurally planning movement throughout the day. The evidence from a review of literature by Dobbins et al. (2013) suggests that effective school-based interventions should include some combination of school curricula, printed educational materials, and likely, though there is less evidence to support it, educational sessions, physical activity specific sessions, and community-based initiatives. School based activities must focus on creating positive attitudes toward physical activity and be structured to progress the development levels of students. Encouragement from teachers to be more 
physically active during the course of the school day will allow students more opportunity to achieve their daily activity goals. Researchers saw that children and adolescents exposed to specific in-school physical activity interventions spent more time engaged in moderate to vigorous physical activity, with results across studies ranging from five to 45 min more, spent less time watching television, results range from five to $60 \mathrm{~min}$ less per day, and had improved VO2max results. These findings further indicate that abilities of in-school physical activity intervention programs.

Technology used to measure, assess and improve physical activity levels are becoming more widely used in all populations with a strong prominence in the school environment. Usage of devices such as heart rate monitors, pedometers and accelerometers are great ways for physical educators to gauge students' activity. They are also helpful for students to begin to learn more about their own fitness capabilities. Research done by Clapham et al. (2015) assessed student feedback after using a heart rate monitor and pedometer intervention program during the physical education classes. Although they did not see a rise in activity levels, they did observe that the children focused on increasing the number of minutes spent in their target heart rate zone rather than amount of physical activity. The researchers conducted interviews with the subjects concerning how they felt about the interventions and noted one student responding about the usefulness of the heart rate monitor by saying: "Just seeing my heart rate because I never really thought of it before" (Clapham et al., 2015). Many times students are not aware of the possible methods that exist to measure activity. By starting children at a young age on the importance of heart rate zones and the benefits of increased heart rate training, it starts them on the right path to help prevent health issues later in life. 
With advances in technology, researchers set to in order to validate the usage of these technological monitoring devices. Common devices are the Actigraph gt $3 x+$, Polar Active accelerometer, Omron HJ-720 and Yamax Digiwalker SW-701. A study completed by Lee et al. (2015) compared the step count validity of these monitors under controlled and free living conditions. The results of this study indicate that the Yamax, Omron, and Actigraph monitors all produced reliable step results at moderate and brisk walking speeds while the Polar Active performed poorly at all speeds. When the monitors were compared during free living, the Yamax, Omron and Actigraph were all comparable with one another. The Polar Active monitor estimated step counts $44 \%$ greater than the Yamax each day. Which shows that the validity of the Polar Active must be taken into consideration when being used in a research setting and further research investigating these monitors is desirable. Puyau et al. (2002) found similar results for the Actigraph in a study. Their research shows that the Actigraph monitor was reliable in the measurement of energy expenditure in children for sedentary, light, moderate as well as vigorous physical activity intensities. For activity monitoring, especially in a school setting, feasibility as well as cost are taken into consideration. It is important for physical educators as well as researchers to use monitoring methods that are not distracting to the students and do not impede on the other aspects of their learning process.

The usage of activity monitoring amongst children is continuing to grow. Many research studies look into activity patterns of children and adults of all ages. An essential part of these studies is to obtain activity data that is representative of the typical activity patterns for an individual on a daily basis. Often times, in order to do this, daily averages are created by condensing and averaging activity data from numerous days. For research purposes, it is necessary to complete monitoring for an amount of days that will correlate to a reliable average 
for individuals' activity patterns. For individuals of all ages, activity patterns vary from day to day, for example, children's activity patterns differ less on a daily basis than adolescents' (36). As stated in a study done by Trost et al. (2000), compared with adolescents in grades 7 to 12 , children in grades 1 to 6 exhibit less day-to-day variability in their moderate-to-vigorous physical activity behavior. As the amount of days increases, the reliability of the results increases. The findings of Trost et al. (2000) indicate that between four to five days of monitoring would be necessary to achieve a reliability of 0.80 in children, and between eight to nine days of monitoring would be necessary to achieve a reliability of 0.80 in adolescents, 0.80 representing a "strong" correlation. Also noted, within all grade levels, a seven-day monitoring protocol produced acceptable estimates of daily participation in MVPA. On the weekends, both boys and girls in grades 1-6 exhibit greater amounts of MVPA than they do during the weekdays. However, in adolescents, grades 7-12, MVPA patterns were greater during the weekdays than the weekends. Results of research done by Tudor-Locke et al. (2004) show that when adult activity patterns are monitored, any three days of the week can provide a sufficient estimate of activity habits. This shows that adults have less variability in their activity habits than children. These findings do not suggest that adults are necessary less active than children simply that adults vary in their activity habits on a daily basis. Research suggests that at least 4 days of activity monitoring in children and at least 3 days of monitoring for adults are needed. As children grow into adolescence, their activity patterns show greater variability and more days of monitoring are necessary.

\section{Summary}

Physical activity and exercise are essential in the prevention of disease and other chronic health issues in U.S. adults and children. There is a strong link between increased physical 
activity patterns and increased levels of health and fitness in vast amounts of research. In addition, there is a significant association between increased physical activity and reduction in body fatness, decreases in cardiovascular disease risk, enhanced bone health, reduced risk of metabolic disease, improved emotional and social health and an increase in psychological wellbeing. With the research suggesting these benefits, there are many studies that show that children of all ages as well as adults are not getting the required amounts of daily physical activity needed to achieve some of these positive outcomes.

It is necessary for children to have opportunities throughout the school day to assist in their achievement of activity recommendations. Promotion and implementation of different activity strategies are likely the most beneficial methods for helping students in their daily activity habits. Research shows that children who participate in daily physical education classes as well as take activity breaks during their core classes have better chances at reaching their daily activity goals.

Further research is warranted to understand in-school elementary students' physical activity habits in order to ensure that schools are doing all that can be done to help students achieve their activity goals. With research showing such strong relationships between physical activity and health outcomes, increasing daily activity habits is vital to a school's curriculum. 


\section{References}

Adkins, M., Bice, M., Bartee, T., \& Heelan, K. (2015). Increasing physical activity during the school day through physical activity classes: Implications for physical educators. The Physical Educator, 72, 173-180.

“An overview of chronic disease prevention." Center for Disease Control and Prevention, 2016

Belcher, B. R., Berrigan, D., Dodd, K. W., Emken, A., Chou, C., \& Spruijt-Metz, D. (2010). Physical activity in US youth: Effect of Race/Ethnicity, age, gender, and weight status. Medicine \& Science in Sport \& Exercise, 42(12), 2211-2218.

Benjamin, R. M. (2010). The surgeon General's vision for a healthy and fit nation. U.S. Department of Health and Human Services. Office of the Surgeon General

Blair, S. N., Davey, S. G., Lee, I., Fox, K., Hillsdon, M., Haskell, W. L., et al.. (2010). A tribute to Professor Jeremiah Morris: The man who invented the field of physical activity epidemiology. Annals of Epidemiology, 20(9), 651-657.

Booth, F. W., Roberts, C. K., \& Laye, M. J. (2012). Lack of exercise is a major cause of chronic diseases. National Institutes of Health, 2(2), 1143-1150.

Carlson, J., Engelberg, J., Cain, K. L., Conway, T. L., Mignano, A. M., Bonilla, E., et al.. (2015). Implementing classroom physical activity breaks: Associations with student physical activity and classroom behavior. Preventative Medicine, 81, 67.

Carlson, J., Sallis, J. F., Norman, G., McKenzie Thomas, Kerr, J., Arrendondo, E. M., et al.. (2013). Elementary school practices and children's objectively measured physical activity during school. Preventative Medicine, 57, 591-596.

"Chronic disease prevention and health promotion." Center for Disease Control and Prevention, 2016.

Clapham, E. D., Sullivan, E., C., \& Ciccomascolo, L. E. (2015). Effects of a physical education supportive curriculum and technological devices on physical activity. The Physical Educator, 72, 102-107.

"Clinical guidelines on the identification, evaluation, and treatment of overweight and obesity in adults.” NHLBI Obesity Education Initiative Expert Panel on the Identification, Evaluation, and Treatment of Obesity in Adults (US), 1998.

Colley, R. (2011). Children's daily step count can be used to gauge physical activity goals. Medicine \& Science in Sport \& Exercise

Dietz, W. H. (1997). Health consequences of obesity in youth: Childhood predictors of adult disease. Pediatrics 
Dobbins, M., Husson, H., DeCorby, K., \& LaRocca, R. (2013). School-based physical activity programs for promoting physical activity and fitness in children and adolescents aged 6 to 18 (review). Cochrane Database of Systematic Reviews, 1(2), 1-7

Dowda, M., Taverno Ross, S. E., McIver, Kerry L., Dishman, R. K., \& Pate, R. P. (2017). Physical activity and changes in adiposity in the transition from elementary to middle school. Childhood Obesity, 13(1), 1-6.

Fogelholm, M., Nuutine, O., Pasanen, M., \& Saatela, T. (1999). Parent - child relationship of physical activity patterns and obesity. International Journal of Obesity, 23, 1262-1270.

Freedman, D., Wang, J., Thornton, J., Mei, Z., Sopher, A., Pierson, R., et al.. (2009). Classification of body fatness by body mass index-for-age categories among children. Journal of American Medical Association Pediatrics, 163(9), 805-810.

Hahn, R., Teutsch SM, Rothenberg RB, \& Marks, J. (1990). Excess deaths from nine chronic diseases in the United States, 1986. Journal of American Medical Association, 264(20), 2654-2661.

Haskell, W. L., Macera, C. A., Pate, R. P., Powell, K. E., Blair, S. N., Franklin, B. A., et al.. (2007). Physical activity and public health updated recommendation for adults from the American college of sports medicine and the American heart association; Medicine \& Science in Sport \& Exercise, 39, 1.

Haskell, W. L., \& Nelson, M. E. (2008). Physical activity guidelines advisory committee report, 2008. U.S. Department of Health and Human Services

Hunt, A. (1965). Physiology and pathology bed rest. British Medical Journal, 2(5461), 583-585.

Kwon, S., Mason, M., \& Welch, S. (2014). Physical activity of fifth to sixth graders during school hours according to school Race/Ethnicity: Suburban cook county, Illinois. Journal of School Health, 85(6), 382-388.

Lee, J. A., Williams, S. M., Brown, D. D., \& Laurson, K. R. (2015). Concurrent validation of the Actigraph gt $3 \mathrm{x}+$, polar active accelerometer, Omron HJ-720 and Yamax Digiwalker SW701 pedometer step counts in lab based and free-living settings. Journal of Sports Sciences, 33(10), 991-996.

McGavock, J. M., Hastings, J. L., Snell, P. G., McGuire, D. K., Pacini, E. L., Levine, B. D., et al.. (2009). A forty-year follow-up of the Dallas bed rest and training study: The effect of age on the cardiovascular response to exercise in men. The Journals of Gerontology Series A: Biological Sciences and Medical Sciences, 64(2), 293-297. 
Mokdad, A., Marks, J., Stroup, D., \& Gerberding, J. (2004). Actual causes of death in the United States, 2000. Journal of American Medical Association, 291(10), 1238-1243.

Morris, J. N., \& Crawford, M. D. (1958). Coronary heart disease and physical activity of work. British Medical Journal, 5111-5120.

Mota, J., Santos, P., Guerra, S., Ribeiro, J., \& Duarte, J. (2003). Patterns of daily physical activity during school days in children and adolescents. American Journal of Human Biology, 547(53) 1-6.

Myers, L., Strikmiller, P., K., Webber, L. S., \& Berenson, G. S. (1996). Physical and sedentary activity in school children grades 5-8: The Bogalusa heart study. Medicine \& Science in Sport \& Exercise, 28(7), 852-858.

Ogden, C. L., Carroll, M. D., Fryar, C. D., \& Flegal, K. M. (2015). Prevalence of obesity among adults and youth: United states, 2011-2014. Center for Disease Control and Prevention.

"Physical activity and health: A report of the surgeon general." Center for Disease Control and Prevention, 2016

"Physical activity and health: The benefits of physical activity." Center for Disease Control and Prevention, 2015

"Physical activity for everyone.” Center for Disease Control and Prevention, 2016

"Physical activity in youth and adolescents." the American College of Sports Medicine, 2015

Puyau, M. R., Adolph, A. L., Vohra, F. A., \& Butte, N. F. (2002). Validation and calibration of physical activity monitors in children. Obesity A Research Journal, 10(3), 150-161.

Taverno Ross, S. E., Downda, M., Dishman, R. K., \& Pate, R. P. (2016). Classes of physical activity and sedentary behavior in 5th grade children. American Journal of Health Behavior, 40(3), 352-357.

Trost, S. G., Pate, R. P., Freedson, P. S., Sallis, J. F., \& Taylor, W. C. (2000). Using objective physical activity measures with youth: How many days of monitoring are needed? Medicine \& Science in Sport \& Exercise, 32(2), 426-431.

Trost, S. G., Pate, R. P., Sallis, J. F., Freedson, P. S., Taylor, W. C., Downda, M., et al.. (2001). Age and gender differences in objectively measured physical activity in youth. Medicine \& Science in Sport \& Exercise, 34(2), 350-360.

Tudor-Locke, C., Burkett, L., Reis, J. P., Ainsworth, B. E., Macera, C. A., \& Wilson, D. K. (2004). How many days of pedometer monitoring predict weekly physical activity in adults? Preventative Medicine, 40(1), 293-299. 
Tudor-Locke, C., Craig, C. L., Beets Michael W., Belton, S., Cardon, G. M., Duncan, S., et al.. (2011). How many Steps/Day are enough? For children and adolescents. International Journal of Behavioral Nutrition and Physical Activity, 8(78), 1-8. 